\title{
Data Analytics of Production Cycle Time for Offsite Construction Projects
}

\author{
Angat Pal Singh Bhatia ${ }^{1 *}$, Sanghyeok Han ${ }^{2}$, Osama Moselhi ${ }^{3}$, Zhen $\mathrm{Lei}^{4}$, and Claudio Raimondi ${ }^{5}$ \\ (1) PhD Student, Department of Building, Civil and Environmental Eng., Concordia University \\ ${ }^{(2)}$ Assistant Professor, Department of Building, Civil and Environmental Eng., Concordia University \\ ${ }^{(3)}$ Professor, Department of Building, Civil and Environmental Eng., Concordia University \\ ${ }^{(4)}$ Assistant Professor, Department of Civil Engineering, University of New Brunswick \\ ${ }^{(5)}$ General Manager, Fortis LGS Structures Inc., Edmonton, Canada \\ *Corresponding author's e-mail: an_hatia@encs.concordia.ca
}

\begin{abstract}
Offsite construction has been widely used in the construction industry. The process improves productivity that leads to shortened project schedule and lower budget. Over the decades, offsite construction industry has continuously evolved with the aspects of management and technology. However, offsite construction companies still have various challenges such as accurately obtaining productivity metrics, which helps in production planning. These challenges result from lack of understanding the process itself because of high variation of wall panel design specifications along with high variability of cycle time at each work station. To solve the problem, productivity data needs to be collected in context to offsite construction. In this paper, a time study was conducted in one of Alberta's-based offsite construction factory. From the collected data and product design specifications, multiple linear regression models were developed to represent the actual work station time. The comparison between actual collected duration and modeled duration for assembly station demonstrate its accuracy that ranges from $80-99 \%$. In the near future, findings will be used for simulation to forecast factory production and optimize the utilization of the resources.
\end{abstract}

\section{KEYWORDS}

Offsite Construction; Time Study; Wall Panel Design Specifications; Multiple Linear Regression.

\section{BACKGROUND AND INTRODUCTION}

Offsite construction, one type of which is panelized construction, has become a popular choice among home builders as the process delivers high productivity and efficiency (Altaf et.al 2017). According to Xie et al. (2017), other potential benefits are better utilization of workers and improve inventory control. In offsite construction, light gauge steel (LGS) panel system has been adopted by construction industry. In this process wall and bathroom panels are prefabricated in the factory and transport to the site for installation (Liu et al., 2015). Moreover, various activities are accomplished in a factory environment, thus makes it a significant option for maximizing production line productivity (Altaf et al. 2017). However, with improving the competitive edges, businesses are striving to achieve optimal productivity by identifying bottlenecks to stay competitive in the market (Huang et al. 2003). 
To improve the industrialized home building production line productivity, application of lean manufacturing, simulation and building information modeling (BIM) were implemented (Altaf et al. 2017). Value stream mapping a lean manufacturing principle was used by Shafai (2012) and Wang et al. (2009) to map the current flow of production line in order to analyze and identify possible bottlenecks. Additionally, Yu (2010) developed the production system by transforming the application of lean principles in the production line. Liu et al (2015) planned the process of panel prefabrication by integrating simulation and BIM. However, in production line, wall panels have unique design specifications such as variation in number of studs, size of door/window etc. This results into a variation at each work station cycle time that increases the idle between stations, thus makes it significant to collect as well as analyze data for realistic production line analysis.

Data analytics is a useful approach to analyze and uncover hidden relationship between the parameters of production line. Moreover, this process helps to evaluate wall panels design specifications that have an influence on production line (Park et al. 2005). For instance, Azimi et al. (2011) introduced real time data acquisition system with simulation to monitor the fabrication of steel projects. Altaf et al. (2017) utilized RFID for data collection and build simulation model to predict work stations processing time. Regression analysis was used by Shafai (2012) to predict cycle time of work stations based on the values of panel design specifications. However, task and specifications of wall panels were different from the current research. Moreover, their study didn't describe the significant factors affecting each work station cycle time.

The objective of the research paper is to analyze time study results of a wall panel production line to reflect the reality of production. To achieve this, the research included the following objectives: (1) conduct time study; (2) identify wall panel design specifications affecting cycle time of each work station; and (3) multiple linear regression model. The regression model considers the time study results and wall panels design specifications to estimate the cycle time at each work station. The model application is presented in LGS production line as a case study. In the following sections a brief description of the LGS production line is presented, followed by a methodology. Regression model results are also discussed and compared with the actual collected time study.

\section{LIGHT GAUGE STEEL FABRICATION PROCESS}

The proposed methodology is tested in the production line of Fortis LGS structures Inc. our collaborator in this research. The Edmonton based company specializes in constructing residential buildings using LGS, an environmentally sustainable solution. The process involves the manufacturing of wall panel components that are transported and installed on site as modules. Figure (1b) illustrates typical wall panel frame components such as studs, cripples, bracing, top and bottom track, dry wall etc. The production line work stations are shown in figure (1a). The process begins with assembly station, where steel studs, tracks, cripples etc. are assembled as per shop drawings and passed to the framing station. At framing station, computer numerical control (CNC) machine is used for pressing studs and tracks to form a rigid frame. The interior wall panels with rim tracks are moved to storage area for shipment and exterior wall panels are transferred to sheathing station. At sheathing station dry walls on wall panels are installed and sent to the panel racks for exterior finishes. Exterior finishes include waterproofing, door/window installation, foaming, rasping, basecoat and skim coat, along with shipment of approved panels. The following section presents the methodology to accomplish the research objective. 


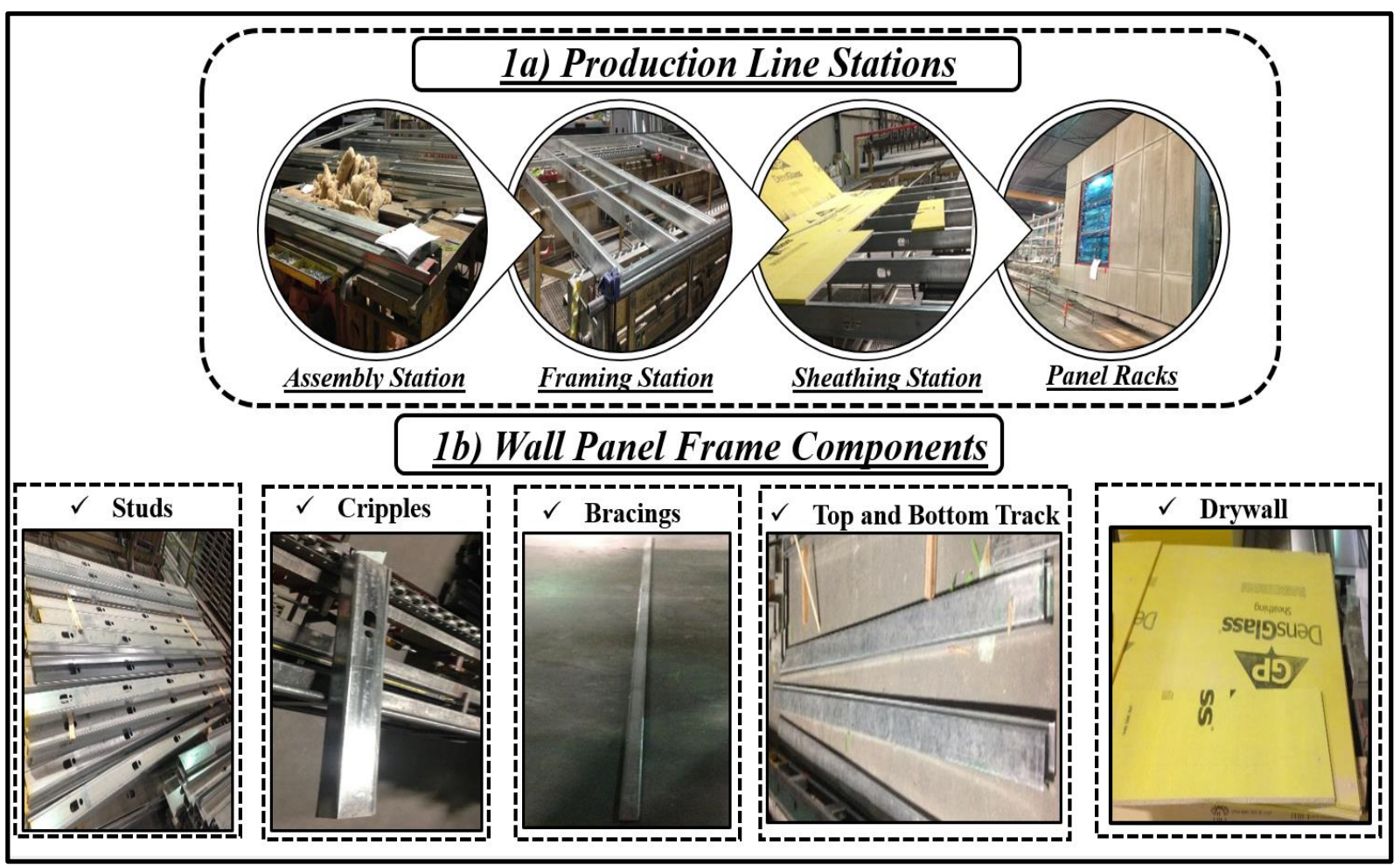

Figure 1 (a \& b). Light Gauge Steel Wall Panels Production Line and Components

\section{PROPOSED METHODOLOGY}

The objective of the paper is to analyze time study results of a wall panel production line. Figure 2 presents the architecture of collecting and analyzing time study results. Wall panel design specifications were identified by observing activities, checking shop floor drawings and consulting plant manager. Multiple linear regression models were formulated to predict the duration of work stations based on design specifications. Below is the detailed description of steps involved.

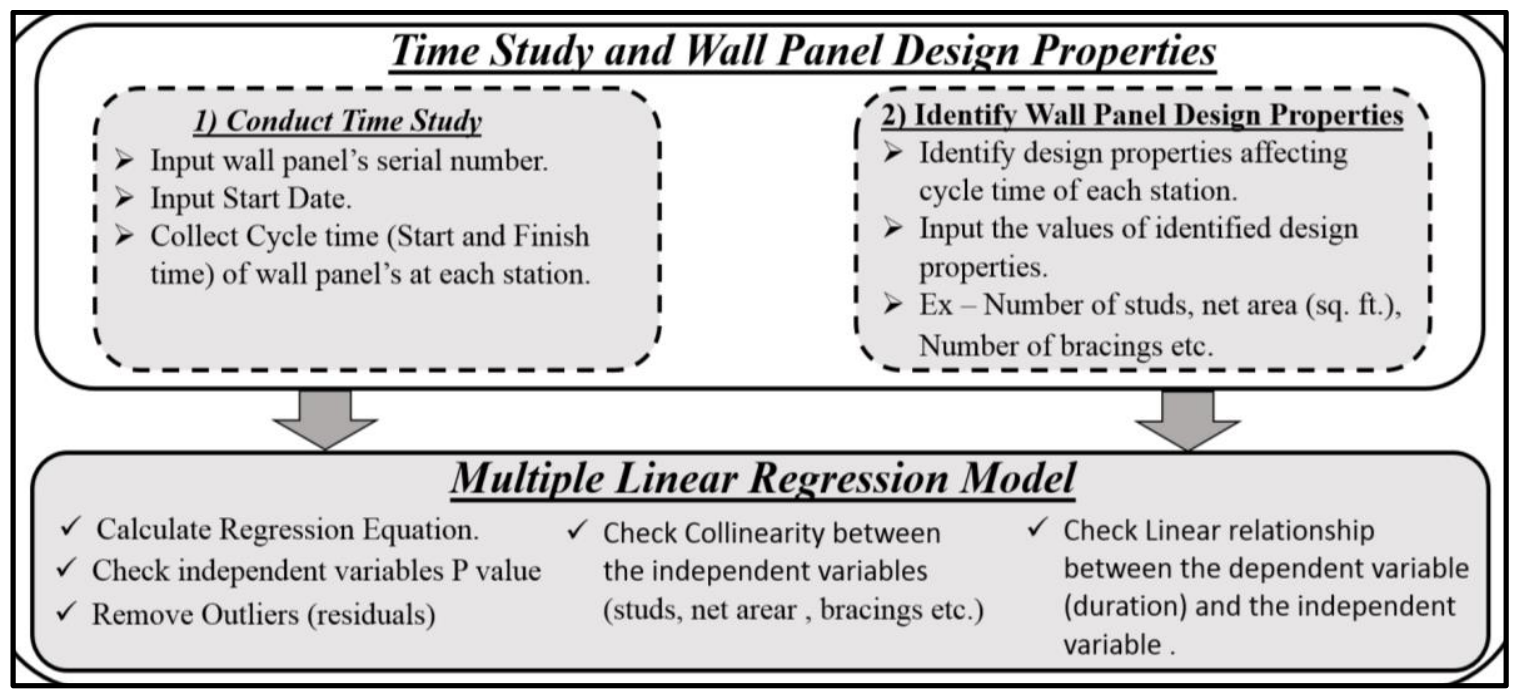

Figure 2. Outline of the Proposed Method 


\section{Time Study}

Production line was observed to understand the standard operation procedures (SOP) of each work station. After that time study was performed from June - August 2018. The data of 150 production cycles of wall panels were recorded in minutes with a stop watch. To collect time data various instructions were followed:1) position in a way that worker's movement was not obstructed, 2) collect the time of qualified and trained workers. The collection process started as first activity started and stopped when final activity completed. For example, at assembly station author started to collect time when workers picked up studs and stopped when the components were wrapped and moved to framing station. The collected data was recorded on a time sheet (see table1), such as panel name, production date, start/finish time, Number of: studs, bracing etc.

Table 1. Wall Panel design property sheet

\begin{tabular}{|c|c|c|c|c|c|c|c|c|c|}
\hline $\begin{array}{l}\text { Panel } \\
\text { Name }\end{array}$ & $\begin{array}{l}\text { Production } \\
\text { Date }\end{array}$ & $\begin{array}{l}\text { No. of } \\
\text { Workers }\end{array}$ & $\begin{array}{l}\text { Start } \\
\text { Time }\end{array}$ & $\begin{array}{l}\text { Finish } \\
\text { Time }\end{array}$ & $\begin{array}{l}\text { Duration } \\
\text { (Min) }\end{array}$ & $\begin{array}{l}\text { No. of } \\
\text { Studs }\end{array}$ & $\begin{array}{l}\text { No. of } \\
\text { Bracings }\end{array}$ & $\begin{array}{l}\text { S.A } \\
\text { Door } \\
\text { (sq.ft) }\end{array}$ & $\begin{array}{l}\text { Net } \\
\text { Area } \\
\text { (sqft) }\end{array}$ \\
\hline I 991 & June.05.2018 & 2 & $\begin{array}{l}2: 20 \\
\text { PM }\end{array}$ & $\begin{array}{l}2: 25 \\
\text { PM }\end{array}$ & 20 & 3 & 2 & 0 & 34.3 \\
\hline I 990 & June.05.2018 & 2 & $\begin{array}{l}3: 05 \\
\text { PM }\end{array}$ & $\begin{array}{l}3: 44 \\
\text { PM }\end{array}$ & 32 & 6 & 3 & 18.3 & 17.1 \\
\hline $\begin{array}{l}\text { CR } \\
901\end{array}$ & June.06.2018 & 3 & $\begin{array}{l}10: 18 \\
\text { AM }\end{array}$ & $\begin{array}{l}\text { 11:02 } \\
\text { AM }\end{array}$ & 44 & 16 & 3 & 24.5 & 159.3 \\
\hline
\end{tabular}

\section{Wall Panel Design Specifications}

The task was to find wall panel design specifications affecting cycle time of each work station. The design specifications were identified by observing the activities, checking shop drawing files and interviewing plant manager. Figure 3 shows the identified design properties affecting assembly station, such as number of cripples, number of studs, length of header and sill track etc. The values of wall panel design specifications were extracted from the shop drawings to create multiple linear.

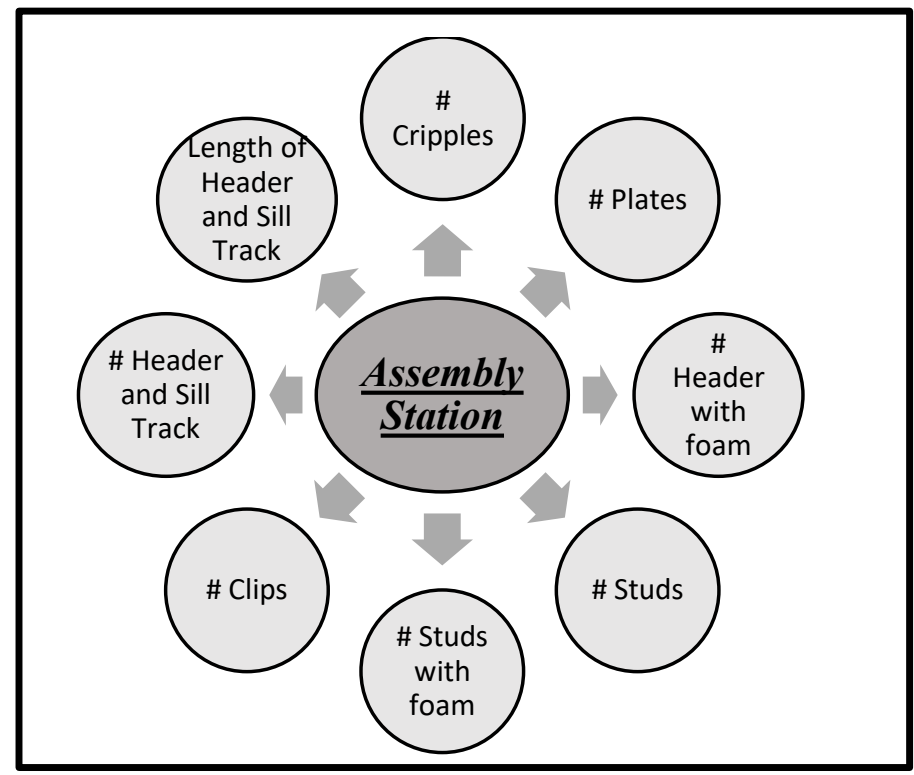

Figure 3. Factors Affecting Assembly Station 


\section{Regression Model}

The formulated models predict the wall panel's duration based on its design specifications. The duration was a dependent variable and design specifications such as number of studs, net area etc. were independent variables. The regression model included two steps; 1) Full Regression modelall wall panel design properties affecting the duration were considered. 2) Final Regression Model - model was formulated after applying backward elimination method and includes design properties that were significant. The independent variables with $\mathrm{P}$ value $>0.05$ were least significant and removed from the model. The reduced model was used because large number of independent variables leads to multi-collinearity and formulate into misleading coefficients. The assumptions checked were, 1) Outliers, 2) Collinearity and 3) Linear relationship.

\section{MULTIPLE LINEAR REGRESSION MODEL RESULTS}

\section{Full Regression Model}

Regression models are formulated based on time study and design properties. Equation 1 shows duration formula for assembly station, where $\mathrm{X}_{\mathrm{S}}, \mathrm{X}_{\mathrm{HT}}, \mathrm{X}_{\mathrm{ST}} \mathrm{X}_{\mathrm{HF}}, \mathrm{X}_{\mathrm{SF}}, \mathrm{X}_{\mathrm{C}}, \mathrm{X}_{\mathrm{CR}}$ and $\mathrm{X}_{\mathrm{W}}$ represents number of: studs, header tracks, sill tracks, header with foam, studs with foam, clips, cripples and workers. The coefficients of variables are interpreted as if number of: cripples, studs and clips are increased by one, then average duration is increased by $1.61,0.79$ and 2.17 minutes. Coefficient of workers is negative and indicates if increased by one then average duration is reduced by 6.16 minutes. The adjusted $\mathrm{R}$ value of 0.27 , shows $27 \%$ variation in duration of wall panel by the design properties considered. Figure 4 shows full regression models of framing / sheathing station.

$$
D_{A}=2.17 X_{S}-3.50 X_{H T}-0.81 X_{S T}-0.07 X_{H F}+3.24 X_{S F}+0.79 X_{C}-6.16 X_{W}+1.61 X_{C R}+17.49
$$

Adjusted $\mathrm{R}$ value $=0.27 ; \mathrm{P}$ value $=0.00032$

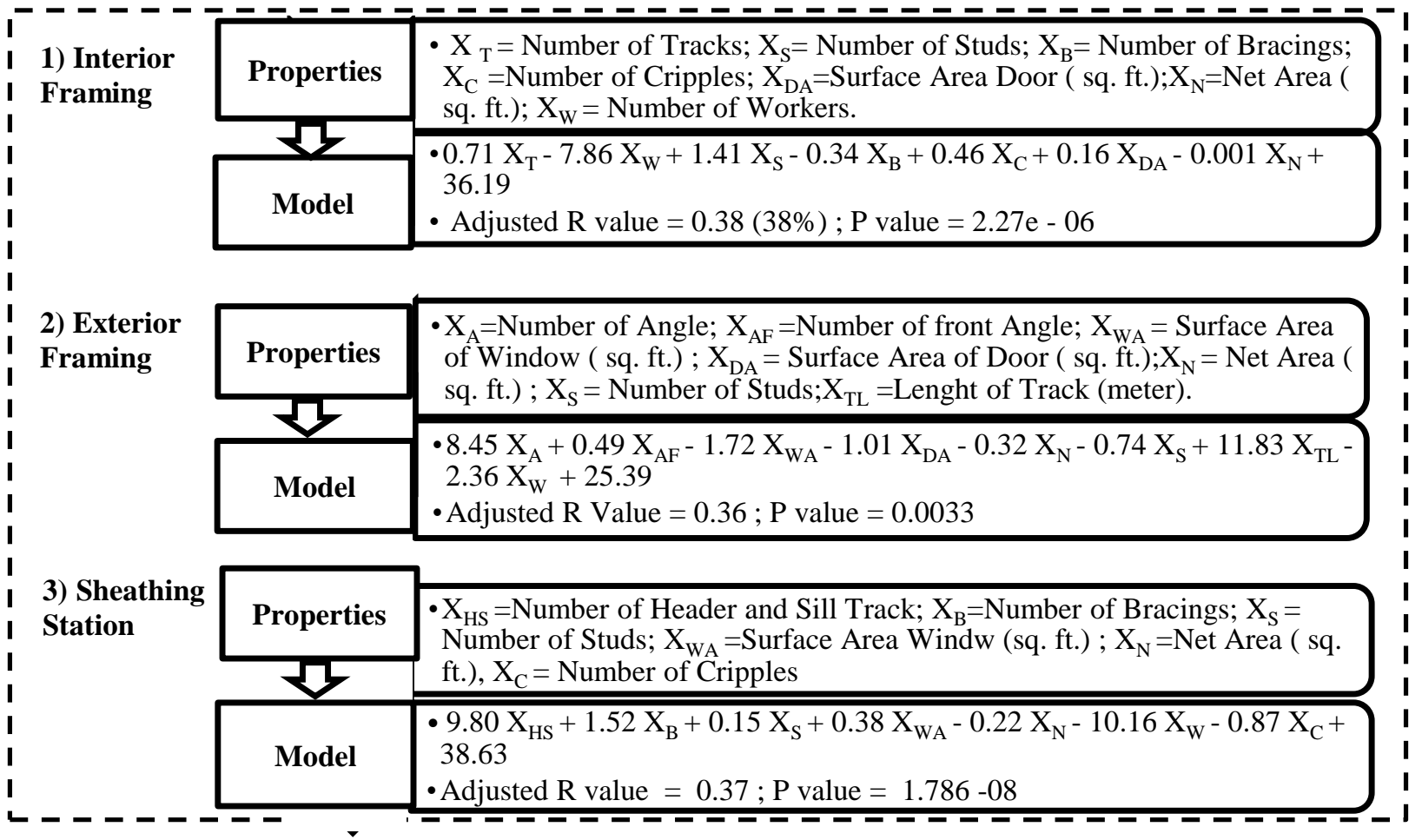

Figure 4. Full Regression Model for Framing and Sheathing Station 


\section{Final Regression Model}

Final regression duration formula is derived after eliminating design specifications that are not significant in explaining wall panel duration. The independent variable with highest $\mathrm{P}$ value $>$ 0.05 was eliminated first and the process continues until all independent variables with $\mathrm{P}>0.05$ were eliminated. Equation 2 shows final duration formula for assembly station. The R square value increases to 0.845 , means $84.5 \%$ of variation in the duration of a wall panels is explained by variation in the value of number of studs $\left(\mathrm{X}_{\mathrm{S}}\right)$ and number of cripples $\left(\mathrm{X}_{\mathrm{CR}}\right)$. The assumptions checked are: 1) Collinearity between number of studs and number of cripples (21\%); 2) Linear relationship between duration and number of studs as shown in figure 5. Figure 6 shows final regression model derived for framing and sheathing station.

$$
D_{A}=6.71+1.32 X_{S}+1.69 X_{C R}
$$

$\mathrm{P}$ value $=2.2 \mathrm{e}-16 ;$ Adjusted $\mathrm{R}=0.845(84.5 \%)$

Duration vs Studs

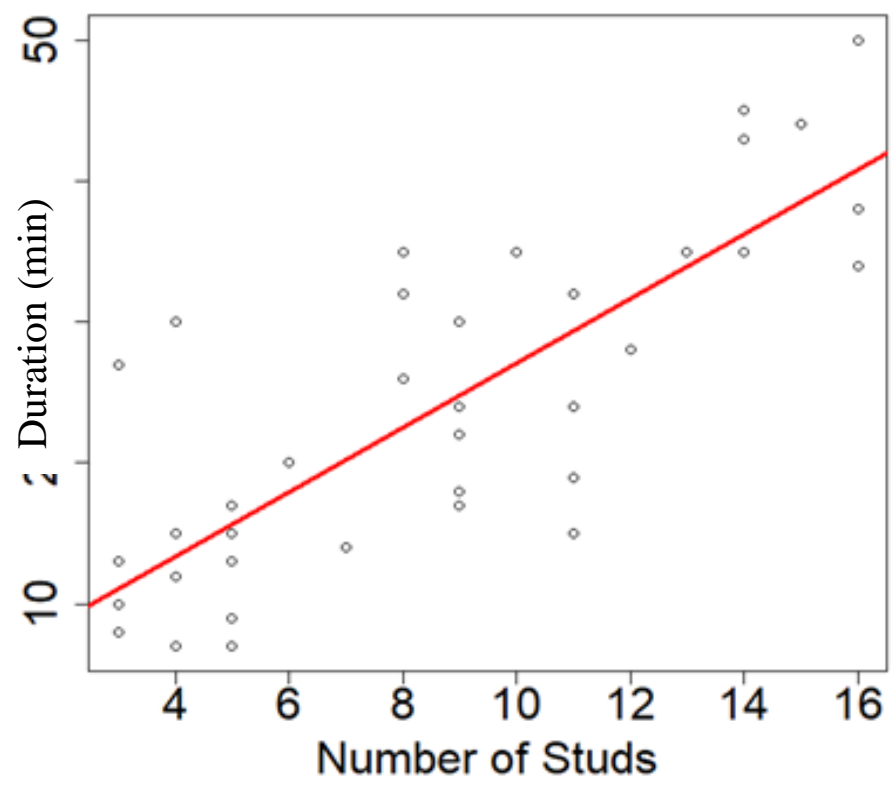

Figure 5. Scatterplot of Duration Vs Number of Studs 


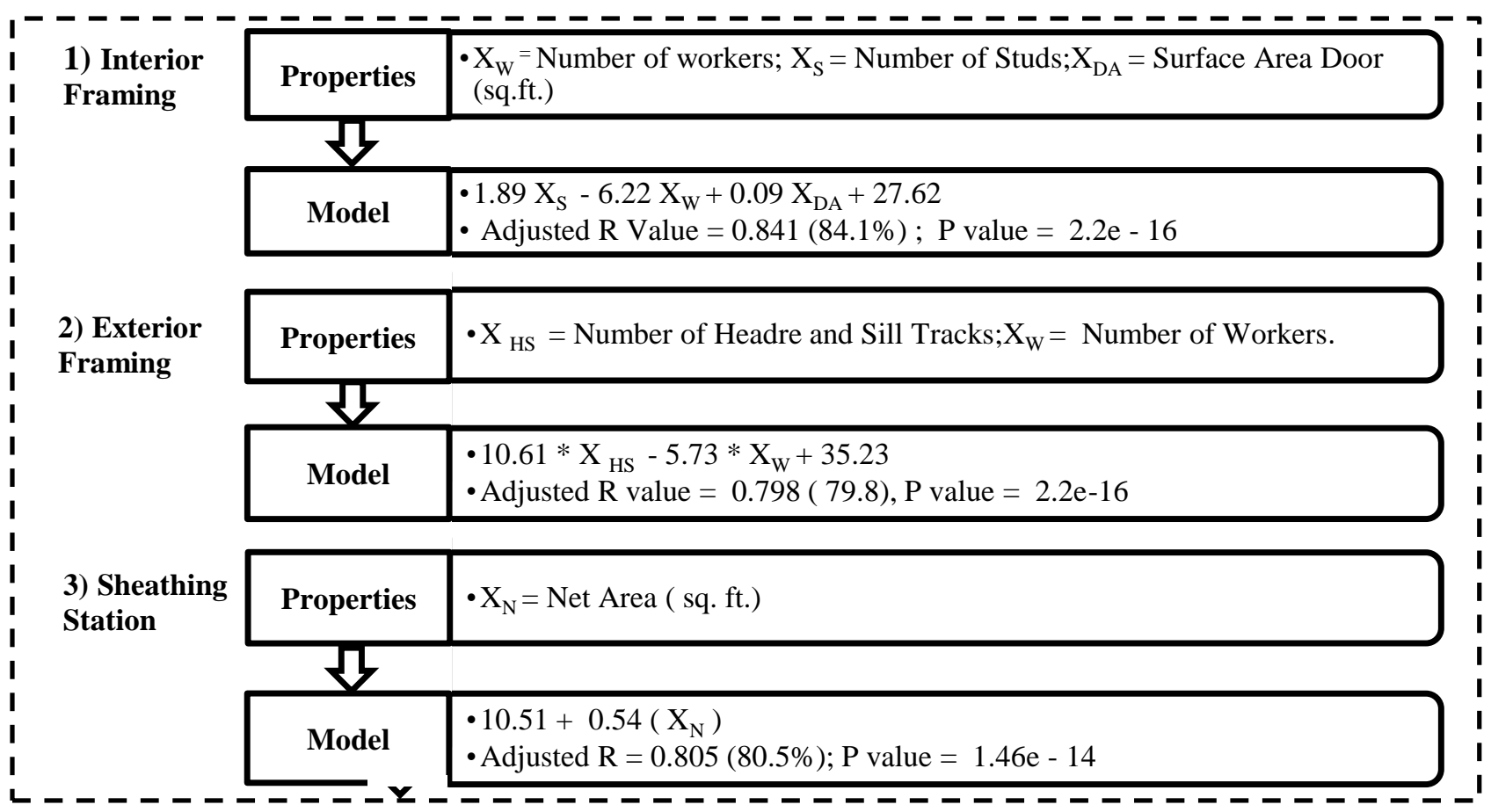

Figure 6. Final Regression Model for Framing and Sheathing Station

Table 7 summarizes the comparison between actual collected duration and modeled duration for assembly station and demonstrates that for most observations the accuracy ranges from $80-99 \%$.

Table 7. Comparison of actual and modeled duration for Assembly Station

\begin{tabular}{cccc}
\hline Observation & Actual Duration & Model Duration & Accuracy (\%) \\
\hline $\mathbf{1}$ & 12 & 11.99 & 99 \\
\hline $\mathbf{2}$ & 13 & 13.31 & 98 \\
\hline $\mathbf{3}$ & 18 & 18.59 & 97 \\
\hline $\mathbf{4}$ & 10 & 10.67 & 93 \\
\hline $\mathbf{5}$ & 38 & 34.59 & 85 \\
\hline $\mathbf{6}$ & 30 & 25.51 & 81 \\
\hline $\mathbf{7}$ & 28 & 22.55 & 78 \\
\hline $\mathbf{8}$ & 24 & 18.59 & 76 \\
\hline $\mathbf{9}$ & 20 & 24.77 & 58 \\
\hline $\mathbf{1 0}$ & 15 & 21.23 & \\
\hline
\end{tabular}


MOC SUMMIT / MAY 2019

\section{CONCLUSION AND FUTURE WORKS}

The focus of paper is to analyze time study results of a wall panel production line. Multiple linear regression was used to formulate duration model of wall panels at different work stations to represent actual station time. The approach proves to be beneficial as it reflects realistic analysis of the production line. The duration derived through regression model was checked with actual data collected. This shows accuracy of the formulated duration formula between $80-99 \%$. However, the current approach of manual data collection is slow and imprecise, therefore difficult to create a historical database for a company. To address this, cloud based tracking application will be used to automate the process of collecting daily/hourly production data of various production stations. The application can be beneficial in tracking production line, cycle time and idle time of each work station. The cloud based tracking application will also help in improving the information flow between the factory (shop floor) and office (administration). In the next stage of research, the developed regression model will be used for simulation and production forecasting.

\section{ACKNOWLEDGEMENTS}

The authors acknowledge the support of Natural Sciences and Engineering Research Council of Canada (NSERC) (CRDPJ 522018-17). The assistance from our research collaborator Fortis LGS structures Inc. company in Edmonton, Canada is also appreciated. Additionally, the support from the Off-site Construction Research Centre (OCRC) of University of New Brunswick, Canada is acknowledged.

\section{REFRENCES}

Altaf, M.S., Bouferguene, A., Liu, H., Al-Hussein, M. and Yu, H., (2018). "Integrated production planning and control system for a panelized home prefabrication facility using simulation and rfid". Automation in Construction, 85, pp.369-383.

Azimi, R., Lee, S., AbouRizk, S.M. and Alvanchi, A., (2011). "A framework for an automated and integrated project monitoring and control system for steel fabrication projects." Automation in Construction, 20(1), pp.88-97.

Huang, S.H., Dismukes, J.P., Shi, J., Su, Q.I., Razzak, M.A., Bodhale, R. and Robinson, D.E. (2003). "Manufacturing productivity improvement using effectiveness metrics and simulation analysis." International Journal of Production Research, 41(3), pp.513-527.

Ikuma, L. H., Nahmens, I., James, J. (2010). "Use of safety and lean integrated kaizen to improve performance in modular homebuilding." Journal of Construction Engineering and Management, 137(7), 551-560.

Liu, H., Altaf, M.S., Lei, Z., Lu, M. and Al-Hussein, M. (2015). "Automated production planning in panelized construction enabled by integrating discrete-event simulation and BIM." 5th International/11th Construction Specialty Conference (pp. 8-10).

Park, H.S., Thomas, S.R. and Tucker, R.L. (2005). "Benchmarking of construction productivity." Journal of Construction Engineering and Management, 131(7), pp.772-778.

Shafai, L. (2012). "Simulation based process flow improvement for wood framing home building production lines". (Doctoral dissertation, University of Alberta).

Xie, H., Chowdhury, M.M., Issa, R.R., Shi, W. (2017). "Simulation of Dynamic Energy Consumption in Modular Construction Manufacturing Processes." Journal of Architectural Engineering, 24(1), p.04017034

$\mathrm{Yu}, \mathrm{H} ., 2010$. "An integrated approach toward lean for production homebuilders". (Doctoral dissertation, University of Alberta). 